\title{
Analysis on Process Management and Its Application in University Library Management
}

\author{
Jing Zhang
}

\author{
Library, Nanjing University Of Finance and Economics, Nanjing Jiangsu, 210023, China
}

Key words: Process management, University, Library management.

\begin{abstract}
Process management as a brand-new management theory started to prevail in 1990s. It has been widely applied in modern business circle. Through detailed analysis of process management, it is found that process management tallies with library management work to certain degree. The integration of process management concept in university library management work can provide favorable support for university library management. Based on brief analysis of process management, this paper analyzes the measures to apply process management in university library management, in the hope of promoting rational application of process management in university library management and enhancing university library management value.
\end{abstract}

\section{Introduction}

As Chinese society gradually enters the era of web2.0, university libraries introduce richer network information resources in the management process and properly adjust the organization and management mode, in the hope of dating to era development trend and offering high-quality book management service fore universities. Under such social background, the total service environment of university libraries changes certainly. The complexity of service objects is stronger, and higher requirements are proposed for comprehensive library management service. Thus, to gain good development in the new period, university libraries should explore book management optimization measures from multiple channels, provide high-quality services foe readers and promote relatively stable development of libraries in the new period.

\section{Application value of process management in university library management}

Process management refers to a group of activities which aim to create relevant value for customers. Process management often involves six aspects: resource input, activity planning, interactions among activities (activity structure), result output, customer and value realization. According to the basic connotation of process management, the whole process of organizational activity may be regarded as a process. In the process system, individuals can not achieve independent value increment. The "process" can play an important role in the whole operation. An excellent process can be transformed into the core competitiveness. The core value of process management lies in the process, and the essence is to provide excellent services. Hence, a more visual judgment can be made for the process. Process management is actually role ability and relation management in the process, which directly reflects ability and relation conformity. If the management problem is analyzed and interpreted from the process perspective, we can find in process management mode, the main mission of process users is to create the specific value for the audiences. What can create value for the audiences is the process. To gain success, process users need to formulate the excellent process operation strategy and favorable process management.

In library management work, library department can organize process management work through gradually exploring and implementing the process of organizational institution and management 
structure with the help of process management to make sure different work and systems have good clearness and to provide corresponding support for comprehensive management work. In the specific process of enhancing process management, libraries can ensure face-to-face communication and exchange between workers and users \& readers through adopting user-oriented and reader-oriented process management mode. Based on all-round analysis of users' needs and readers' needs, effective service strategies can be confirmed on the basis of users' interests and readers' interests. Rational introduction and use of process management concept and method in university library management can achieve optimization and adjustment of original functional department. Then, the service process oriented to all readers and process-based service system can be constructed. In this way, management norm of university libraries can be significantly enhanced. Besides, service efficiency and effect will be more significant. Therefore, process management plays an important role for good operation and modern development of university libraries.

\section{Specific measures to implement process management for university libraries}

Based on the application advantage of process management in university libraries, in order to gain certain development opportunity and ensure development effect in the process of exploring modernization construction and development, university libraries may try to introduce process management concept in the specific management practice and organically combine process management with university library management work to achieve optimization and innovation of comprehensive management work of university libraries, guarantee overall exertion of process management functions and provide a solid guarantee for university library development.

\section{To actively establish university library service process management system}

The construction of process management system is an important method to rationally apply process management mode. In the process of applying process management mode to enhance library management work, libraries can apply process management system to ensure actual effect of process management work, promote overall exertion of process management functions and provide good support for comprehensive management of university libraries only when they form correct cognition of process management and actively explore construction of process management system ${ }^{[1]}$. To be specific, university library service process management system mainly includes four parts: process operation system, process operation supervision system, organizational structure of process management and process appraisal system. The process operation system needs to specify the service processes included in the library management activity, and specify how to rationally operate these service processes and ensure the management effect. Organizational structure of process management refers to leadership, organization and supervision institutions set up in the university library management department in order to guarantee process operation efficiency and effect in the process of implementing process management. It also includes the responsible person and responsibility partition statement. Process operation supervision and appraisal system refers to the appraisal system and incentive system suitable for the service process in the process of implementing process management. The construction of service process management system is a complex system project and involves process survey, operation, comprehensive management, supervision and monitoring of process operation. Only when the comprehensiveness and systematicness of process management are ensured under the support of service process management system can the important functions of process management be really exerted, meanwhile, all-round optimization of library management work can be promoted, and better library service can be provided for university education and scientific research work.

\section{Normative management and specific implementation of core process in university libraries}

The exploration of process management standardization is the foundation of implementing process management and ensuring actual effect of process management. Based on all-round analysis and exploration of process management, the difficulty of normative management during implementing 
process management mode is fully considered, and a long process is needed. Thus, to ensure the effect of process management, normative management of core process should be carried out first. Then, with the radiation effect of core process, normative and standardized development of the whole process management of libraries can be facilitated.

After university libraries apply process management method to carry out all kinds of management work, in order to achieve management and planning of core service process, the key work is to correctly recognize core service and process and then actively explore measures of normative management by combining actual needs of core service and process to further highlight the value of process management and provide important guarantee for all-round optimization of comprehensive management work of libraries. After overall analyzing and studying the core service process Chinese libraries, relevant researchers have found that Chinese university libraries show certain construction characteristics in the construction and development process, and the core service process is reflected in the three aspects. To confirm the core service process of libraries is to analyze the core competence of libraries from the perspective of social system. In fact, the university library is a special social system with the ability to guarantee knowledge freedom. From the system perspective, the core competence of libraries can be regarded as an orgasmic intergrant of technology, skill, operation, organization, management and culture etc. From the service perspective, the core competence of libraries is knowledge service ability. From this perspective, library management work includes the core competence, and the management process which can offer the great value increment for readers and users is the process in the core position ${ }^{[2]}$.

In current network environment, comprehensive service process of libraries have shown certain new change and development trend due to the influence of network information technology and internet information dissemination mode. The service process involved in traditional management work needs to be planned and managed again. Management organization structure of libraries and relevant departments also need to combine service process management thought to carry out proper adjustment. If comprehensive organization flow of libraries is planned and innovated in combination of service process thought, the service ability under library process management can be further enhanced, and libraries can gain more stable development in the new period ${ }^{[3]}$. Library service process is properly adjusted by combining universal application of network information technology and the changes of university libraries in the information era. The construction of new service process should be based on recognition and definition of core service process. The core service process of university libraries in the network era mainly includes information resource evaluation process, information resource service process and information resource construction process. In other words, libraries should combine management demand of core service process under network era to explore normative management strategy and ensure the actual effect of process management in the process of implementing service process management. Only in this way, the functions of service process management can be highlighted furthest, and process management effect will be further enhanced. Therefore, process management plays an important role for stable development of libraries.

\section{To create organizational culture of library team matched with process management}

After the core processes are recognized and implemented, libraries should construct the process team matched with the core process management, take the product as the core, and regard gradual improvement of user satisfaction as the basic objective to establish rational organizational culture of process team and provide all-round support for optimization of process management work in order to facilitate the effect of university library process management, ensure the specific implementation effect of all core processes and provide favorable support for achieving strategic development objective of libraries. During constructing organizational culture of library process team, it is necessary to note that process management work of process team is the fundamental unit form and can offer good support for smooth implementation of process management work. Only with the help of high-quality process team, process management objective can be achieved smoothly, and university libraries can gain better development opportunities in the new period ${ }^{[4]}$. Thus, in order to 
ensure team quality and the exertion of team functions in the process of building process team, it is required to properly integrate teamwork, honesty and sharing ideas, provide scientific guidance for process team building, make sure the process team can support optimization of process management work, promote enhancement of overall service level of university libraries and facilitate optimization and development of libraries in the new period.

\section{To enhance library information-based and network-based construction based on process management application}

Under the effective support of process management, university libraries can further highlight comprehensive management advantage in the information era in the construction and development process, then actively explore information-based and network-based development direction and ensure era characteristics of library construction and management. To be specific, since the good process management effect needs favorable IT technology as the effective support in the process of applying process management mode, university libraries try to introduce information technology in management work in order to ensure the implementation effect of process management. Then, through rationally applying advanced information technology and network technology, and constructing integrated information office management platform and integrated subject knowledge service platform in comprehensive library management system, management personnel of libraries can provide favorable exchange and information services for users and readers through the platforms to further improve overall work efficiency and ensure further enhancement of comprehensive service ability of libraries on the basis of promoting resource sharing ${ }^{[5]}$. Only through enhancing information-based and network-based construction of libraries based on process management, university libraries can explore new development paths in the development process, grasp the development advantage and offer all-round services for education, study and scientific research of university teachers and students and make sure the functions of university libraries are exerted fully.

\section{Conclusion}

In conclusion, for university libraries, the exploration of process management is a new trial of library management department and reflects the innovation and reform of library management. Replacing traditional management mode with process management in library management can supplement and improve management methods in the traditional mode, and the overall management level of libraries will certainly further improve. Besides, this has important influence on library management effect. Thus, under current social background, university libraries should enhance attention to process management, promote innovation of overall management mode, ensure management effect and provide favorable support for stable development and modernization construction of university libraries.

\section{References}

[1] Wang Junwu, Research on Building up Processed-oriented Organization Model in the Library, New Century Library, 2013(1):49-51,48.

[2] Ma Tianshu, The Design on Reading Process of University Library Based on Process Management, Shanxi Library Journal, 2014(5):46-50.

[3] Zhang Xiangyun, Library Service Process Management Oriented to Reader Service, The Library Journal of Shandong, 2013(1):47-50.

[4] Sun Yue, Yang Xinya, Deng Lingling et al., Inventory Work of the Library Based-on Process Management: A Case Study of Chongqing University Library, Journal of Academic Libraries, 2012,30(3):50-53. 
[5] Dong Han, Yuan Lin, Items and Process Management of Libraries' Digital Information Services A Case Study on Tsinghua University Library Academic Information Resource Portal, New Century Library, 2012(3):43-46. 